\title{
O CYBERBULLYING NO CONTEXTO ESCOLAR E OS DESAFIOS PARA PROMOÇÃO DE UMA CULTURA DA PAZ
}

\author{
Deise Teresinha da Silveira Pereira ${ }^{1}$ \\ Evandro Alves ${ }^{2}$
}

\begin{abstract}
RESUMO
Este artigo é derivado da pesquisa desenvolvida como forma de conclusão do curso de Especialização em Mídias da Educação (3á edição) realizado na Universidade Federal do Rio Grande do Sul. Na contemporaneidade, a utilização das tecnologias da educação e informação como um instrumento mediador das relações sociais, internas e externas à escola, é cada vez mais presente e relevante. Em função disso, evidenciam-se incertezas e lacunas da formação inicial e continuada dos docentes, muitas do ponto de vista da atuação pedagógica neste contexto. Uma das questões candentes nessa conjuntura, principalmente dentro do contexto escolar, são ações de agressão on-line, denominado cyberbullying. Partindo do pressuposto de que a escola é um espaço de diversidade, heterogêneo, e de convivência com o/a outro/a, cabe principalmente a ela prever respostas e construir ações no intuito de combater tal fenômeno. Neste sentido, a presente investigação busca compreender como o cyberbullying incide sobre a escola e suas implicações no contexto. De caráter qualiquantitativo, a pesquisa se apresenta como estudo de caso com os/as alunos/as de duas turmas do Ensino Médio de uma escola da rede Estadual, localizada na região metropolitana de Porto Alegre. O instrumento de coleta de dados foi um questionário respondido individualmente pelos/as alunos/as. Assim o estudo busca contribuir para a compreensão das dinâmicas do cyberbullying no contexto escolar, tendo em vista estabelecer estratégias para dirimir esse fenômeno, no espírito do desenvolvimento de uma cultura de paz no ambiente escolar, tanto em atividades presenciais, quanto na vida on-line que the acerca.
\end{abstract}

Palavras-chave: bullying; cyberbullying; TICs; cultura juvenil; cultura de paz.

\section{ABSTRACT}

This paper is based on an end-of-course research developed for the Educational Media Specialization (3ำedition) in Universidade Federal do Rio Grande do Sul. At the present time, the use of information and educational technologies as a tool to mediate social relations, inside and outside school, is increasingly present and relevant. Due to this fact, uncertainties and gaps in the initial and continuous qualification of teachers become evident, many of them concerning the pedagogicalaction in this context. One of the main issues about this conjuncture, mostly in the school context, is online harassment, called cyberbullying. Relying

1 Professora da Rede Estadual de Ensino do Rio Grande do Sul/RS - e-mail: deipe2004@hotmail.com

2 Professor da Faculdade de Educação (FACED) da Universidade Federal do Rio Grande do Sul (UFRGS) e-mail: evandarilho@gmail.com 
on the assumption that the school is a diverse environment in which people coexist and relate socially, the responsibility to provide answers and build actions to fight such phenomenon falls mainly on the school. In this sense, the present investigation aims to understand how cyberbullying affects school and its implications in the context. This qualitative-quantitative research is designed as a case study of High School students from two classes of a state school located in the metropolitan area of Porto Alegre. An individual questionnaire answered by the students was used as data collection tool. This study aims at contributing to the understanding of cyberbullying dynamics in the school context, bearing in mind the purpose of establishing strategies to stop this phenomenon, in the spirit of promoting a culture peace in the school environment, both in classroom ativities and online life that surrounds school.

\section{Keywords: bullying; cyberbullying; TICs; youth culture; culture of peace.}

\section{APRESENTAÇÃO}

A presente pesquisa foi realizada em uma escola pública de ensino médio situada na região metropolitana de Porto Alegre, tendo como definição o método de estudo de caso. Neste sentido foi escolhida para a pesquisa duas turmas de $1^{\text {a }}$ ano do ensino médio. Este trabalho busca incentivar os demais profissionais da educação a conhecerem e identificarem o fenômeno cyberbullying, manifestando capacidade ética de atuar como agentes de mudança, em busca da qualidade de vida de toda comunidade escolar, tendo por referência a cultura da paz.Nesse sentido, os questionamentos norteadores da pesquisa são: Como o cyberbullying se apresenta na instituição em estudo? É possível caracterizar as dinâmicas pelas quais ele ocorre? Os dados dessa pesquisa foram analisados através de uma abordagem qualiquantitativa, tendo em vista que houve a necessidade de tramitar e utilizar ambas as metodologias realizando assim uma conciliação metodológica. Deste modo Minayo et al (2002), afirma que as relações entre as metodologias devem ser pensadas de forma que uma complete a outra aprofundando os significados das questões, onde um método completará o outro. Objetivo deste estudo de caso é o de fornecer subsídios aos profissionais da educação para o entendimento de futuras estratégias de esclarecimento e reflexão voltada para o enfrentamento da questão no contexto escolar. Cabe salientar o caráter implicado da pesquisadora no contexto de investigação, uma vez que ela também atua no espaço investigado como orientadora educacional. Dessa forma, em uma nota metodológica, quando se fez necessário, utilizaram-se registros do cotidiano educacional investigado, derivados da atividade profissional da pesquisadora para trazer mais elementos do contexto da investigação. Essas ocorrências estão devidamente explicitadas ao longo do artigo. Cabe ainda salientar que, neste escrito, apresenta-se o recorte dos dados coletados, enfatizando as questões advindas dos questionários preenchidos individualmente pelos respondentes. 


\section{TICs na Educação, Culturas Juvenis, Bullying, Cyberbullying: Problematizações para uma Cultura de Paz}

Na contemporaneidade, um dos principais desafios que se impõe aos educadores/as é o de repensar a educação para além do computador e internet, que se encontram presentes em grande parte das escolas. Vivemos um momento em que as tecnologias fazem parte do dia-a-dia das pessoas em casa, no trabalho e ambiente escolar. Essa relação diária com a interconectividade é cada vez mais abrangente, através de computadores, tablets e smartphones, atingindo a todas as classes socioeconômicas.

A Internet passou a ser a base tecnológica para a forma organizacional da era da informação: a rede sendo uma ferramenta que faz parte do dia-a-dia de grande parte das casas e escolas dos estudantes, contribuindo de maneira cada vez mais veloz para a construção de um mundo interconectado onde os organismos culturais acontecem, através também dos saberes compartilhados (CASTELLS, 2003). Dessa forma, temos uma popularização cada vez maior, no meio social brasileiro, de uma cybercultura (LÉVY, 2001), na qual as relações sociais acontecem e são mediadas através da rede, em um mundo interconectado, estabelecendo novas formas de comunicação e provocando oportunidades e desafios. Nesta perspectiva, a presença das TICs na escola:

[...] pode representar um movimento ímpar, uma vez que nos permite
pensar na redução das distâncias, numa maior integração das escolas
entre si e com o mundo contemporâneo; não somente como
consumidoras, mas como possibilidades de produzir conhecimento e
de fazer de cada espaço escolar um lugar de produção coletiva, no
qual sejam constituídas interações não-lineares e onde sejam
fortalecidas essas redes de relações (SANTOS, 2002, p. 49).

Entretanto, saber utilizar as tecnologias não é suficiente. Há a necessidade da construção de habilidades e comprometimento para aprender a utilizar as mais variadas possibilidades que as tecnologias têm nos proporcionando. Este aprendizado deve ser voltado a reflexão para uma ação de análise, organização e tomadas de decisões para resolução dos problemas de forma crítica e responsável.

Neste sentido a partir das observações realizadas na escola onde atuo como orientadora educacional se faz necessário repensar o uso das tecnologias da informação e comunicação a favor de práticas significativas voltadas para construção de sujeitos que se respeitem e passem a construir uma postura ética diante das variadas possibilidades que lhes são apresentadas ao navegar na rede e fora dela para que as construções possam se dar com alteridade entre os sujeitos inseridos e participes da e na educação formal. A partir dessas ressalvas, observa-se que, na realidade desta escola, as relações entre os alunos/as que vivem sua juventude não são fortalecidas com uso das tecnologias e que, ao contrário do que se esperava, os recursos tecnológicos que a mesma dispõe estavam gerando conflitos e mal-estar entre os/as alunos/as.

Dentre os desafios, nos confrontamos com necessidades não somente técnicas, no que diz respeito à infraestrutura de redes, por exemplo, mas também éticas, com relação à liberdade individual, à configuração do que é público e do que é privado na cultura digital e à construção dos limites entre o que se pode ou não fazer na vida on-line. Desta maneira, devemos, enquanto educadores, 
estar atentos para utilização da cybercultura em favor da construção do conhecimento e do respeito à constituição da subjetividade.

Em específico quanto a juventude, Dayrell (2003) afirma que na contemporaneidade existe a necessidade de problematizar o processo de socialização juvenil e o espaço que ele ocupa no contexto da escola, pois esses sujeitos sociais têm suas próprias características e que dentro do contexto social. Essas especificidades sobre a juventude se apresentam dentro da heterogeneidade das diversas formas de ser jovem na contemporaneidade. Dessa maneira, o autor afirma que a juventude seria:

(...) como parte de um processo mais amplo de constituição de sujeitos, mas que tem especificidades que marcam a vida de cada um. A juventude constitui um momento determinado, mas não se reduz a uma passagem; ela assume importância em si mesma. Todo esse processo é influenciado pelo meio social concreto no qual se desenvolve e pela qualidade de trocas que este proporciona (DAYRELL, 2003, p. 42).

Esses apontamentos encontram ressonância no entendimento de juventude presente na Diretrizes Curriculares Nacionais para o Ensino Médio (BRASIL, 2011), considerada como:

\begin{abstract}
Condição sócio-histórico-cultural de uma categoria de sujeitos que necessita ser considerada em suas múltiplas dimensões, com especificidades próprias que não estão restritas às dimensões biológica e etária, mas que se encontram articuladas com uma multiplicidade de atravessamentos sociais e culturais, produzindo múltiplas culturas juvenis ou muitas juventudes. Entender o jovem do ensino médio dessa forma significa superar uma noção homogeneizante e naturalizada desse estudante, passando a percebêlo como sujeito com valores, comportamentos, visões de mundo, interesses e necessidades singulares (BRASIL, 2011, p. 12).
\end{abstract}

Dentre os muitos aspectos referentes à juventude, é cada vez mais relevante a utilização das tecnologias digitais para a mediação das relações interpessoais. Destaca-se também a avassaladora presença destes nas redes sociais. Estar conectado as redes sociais é alusão das diversas possibilidades de observação das relações sociais digitalizadas como resultado das novas formas de interação social. Para Recuero (2009) uma rede social é definida a partir dos seguintes elementos: (1) os atores sociais (pessoas, instituições ou grupos; os nós da rede); e (2) suas conexões (laços de comunicação e de interação). Na contemporaneidade, as redes sociais são as ferramentas mais importantes da comunicação mediada pelo computador (RECUERO, 2009).

Cabe aos educadores refletir sobre as implicações que estas "arenas públicas digitais" têm sobre as relações interpessoais, especificamente sobre a juventude, configurando, talvez, modulações nas próprias formas de ser jovem na contemporaneidade. Dessa maneira, surge a necessidade de observar como estes jovens estão utilizando os computadores da sala de informática e as demais tecnologias digitais, bem como de que maneira eles/elas estão lidando com os aspectos on-line do seu cotidiano.

Em específico, interessa a esta pesquisa, e trata-se da motivação inicial do trabalho, a constatação na escola em estudo, na qual tenho a função de orientação educacional que, muitas vezes, os/as alunos/as ficavam sozinhos/as no laboratório, fazendo uso dos computadores e principalmente das redes 
sociais. Não raro, nestes casos, as redes sociais como o facebook serviam como subsídio a prática ao bullying virtual, ou também chamado de cyberbullying.

Fante (2005), aponta que Dan Olweus descreveu alguns critérios para a diferenciação entre brincadeiras entre pares e o fenômeno bullying que, muitas vezes, passa desapercebido e que, geralmente, é confundido com brincadeira, mas que se trata, na verdade, de uma demonstração de sadismo. bullying deriva da palavra inglesa bullly que, traduzida para o português, significaria, inicialmente, "brigão". Temos aqui um problema de tradução, pois acaba associando bullying à violência física, quando o fenômeno é mais amplo. Neste estudo, bullies são pessoas que têm prazer em maltratar, agredir intimidar e humilhar outros sujeitos ou até mesmo grupos de sujeitos, utilizando-se ou não da violência física.

Deste modo com a popularização das tecnologias digitais e da conectividade via Internet, o bullying se reconfigura no contexto da via on-line, e ganha contornos do que hoje denominamos cyberbullying. Conforme Silva (2010), o cyberbullying acontece a partir do advento e popularização das TICs no meio social, pois é por intermédio dos recursos tecnológicos que o agressor se utiliza para atacar suas vítimas.

Referimo-nos à agressão, quando ocorrida na componente on-line do cotidiano destes estudantes, como cyberbullyinng, uma atitude que acontece através do "mundo Virtual", ou seja, é o bullying gerando e alimentando a violência principalmente pelos meios de tecnologia. Para Fante e Pedra (2008, p. 65),

\begin{abstract}
$\mathrm{Na}$ sua pratica, utilizam-se modernas ferramentas da internet e de outras tecnologias da informação e comunicação, móveis ou fixas com o intuito de maltratar, humilhar e constranger. É uma forma de ataque perversa. A diferença está nos métodos e nas ferramentas utilizadas pelos praticantes. O bullying corre no mundo real, enquanto 0 cyberbullying ocorre no mundo virtual. Geralmente nas outras formas de maus tratos a vítima conhece seu agressor, sejam ataques diretos e indiretos. No cyberbullying, os agressores se motivam pelo "anonimato", valendo-se de nomes falsos, apelidos ou fazendo-se passar por outras pessoas.
\end{abstract}

Matos et al (2009) afirma que cyberbullying é uma extensão do bullying e o conceitua da seguinte maneira:

\begin{abstract}
Nesta perspectiva, o problema do cyberbullying surge com características semelhantes ao bullying tradicional - assente numa assimetria de poder entre agressores e vítimas e responsável por causar danos psicológicos de longo termo nas vítimas, que podem ir da baixa auto-estima ou depressão, até ao insucesso escolar e ao suicídio - com a diferença de ser perpetrado mediante o uso de meios electrónicos (MATOS et al, 2009, p.17).
\end{abstract}

Portanto, cyberbullying é um conjunto de condutas intencionais, que se repetem e incitam a agressividade dentro do espaço virtual. Neste sentido, as perguntas orientadoras deste estudo seriam: Como o cyberbullying se apresenta nesta escola? Quais suas dinâmicas? Seria possível caracterizar o contexto e/ou motivações pelos quais ele ocorre? O interesse deste estudo, com tal levantamento, é a constituição, a partir do local de fala da orientação educacional, de estratégias para enfrentamento dessa questão. 
Busca-se assim, como objetivo geral deste trabalho contribuir para 0 delineamento das dinâmicas pelas quais o cyberbullying se apresenta em instituições escolares do ensino médio e estratégias para prevenção alicerçadas numa cultura para paz, definida pela Organização das Nações Unidas como um conjunto de valores, atitudes, tradições, comportamentos e estilos de vida, fundada no respeito integral à vida e no agenciamento dos direitos humanos $e$ das liberdades básicas, fornecendo a promoção da paz entre todos os seres humanos e nações". (ONU, 1999). Uma educação pela paz consiste em estratégias para fazer valer o respeito à vida e aos direitos humanos.

Assim, ao adentrar no universo particular das escolas, em seus processos educativos observamos a diversidade de práticas que colaboram para 0 afastamento de uma cultura de paz. De acordo com Guimarães (2005) a cultura para paz começa a ser discutida no contexto educacional nacional. Importante notar que as práticas sociais para estabelecer uma cultura de paz só podem ser implementadas a partir de uma ampla compreensão do significado da paz não como construto teórico, mas como parte de um conjunto de práticas. Com o reconhecimento da diversidade humana que nos cerca em qualquer esfera social, seja ela nas relações presenciais ou virtualizadas. Reconhecimento alicerçado nos seguintes princípios, conforme, Beust (2005, p. 15-16):

[...] a atitude dialógica e a unidade na diversidade. A atitude dialógica nos coloca num permanente diálogo com o outro, conosco mesmos, com o real, com o ideal, com a vida. Esse diálogo precisa estar baseado num profundo respeito pela diversidade humana. Mas também precisa estar alicerçado numa igualmente profunda certeza da unidade fundamental da humanidade.

Neste sentido, os dados a serem apresentados a seguir buscam mapear a conectividade e usos das tecnologias pelo grupo participante da pesquisa, de forma a refletir sobre o fenômeno cyberbullying, sua manifestação no contexto específico e possíveis implicações no cotidiano escolar. Apresenta-se aqui um recorte de um estudo mais amplo, que, através de questionários individuais, perguntava pelas condições de conectividade e pelas percepções do grupo acerca do fenômeno cyberbullying.

\section{Contexto da Experiência, apresentação e análise de dados}

A pesquisa foi uma oportunidade de observar o que acontece no contexto do grupo em estudo, através do olhar da orientadora escolar junto aos alunos/as de duas turmas do primeiro ano do ensino médio, perquirindo as formas pelas quais acontecem as relações com as tecnologias e entre seus pares, em específico, sobre o cyberbullying. $\mathrm{O}$ grupo respondente é de 44 respondentes, dividida em duas turmas. A turma A é composta por 24 alunos/as, destes alunos/as 15 (quinze) são meninas e 9 (nove) são meninos, sendo que em pesquisa na secretaria da escola ao realizar a matricula os alunos/as auto declaram-se nas opções branco, amarelo, pardo, negro. Desses/as alunos/as 14 (quatorze) se declaram negros/as e (dois) dois se declaram pardos/as, restando assim oito alunos/as que se declaram brancos/as. Na turma B conta com 20 alunos/as, sendo 11 (onze) meninas e 9 (nove) meninos. Nesta turma 11(onze) se declaram negros/as e 9 (nove) se auto declaram brancos/as. 
Pelos dados levantados, a pesquisa identificou que a maioria dos jovens estudantes no ensino médio passam grande parte do tempo conectado. $91 \%$ dos estudantes ou estão sempre conectados ou utilizam muito a Internet (Figura 1). A forma de conectividade desses estudantes se deve ao uso de smartphones, (Figura 2). O grande índice de respondentes que costumam usar a Internet de todos os lugares, $86 \%$ dos respondentes (Figura 3), corrobora a grande utilização da telefonia móvel como forma de conexão neste grupo.

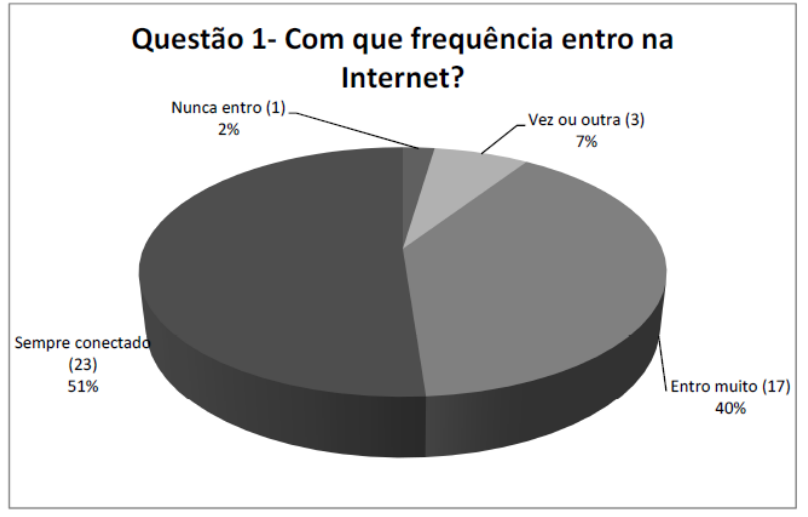

Figura 1- Questão 1 - Com que frequência entro na Internet? Fonte: Da autora

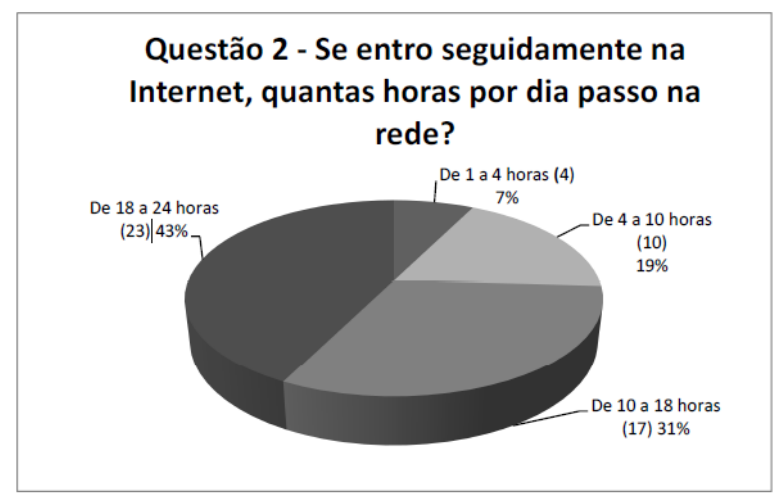

Total respondentes: 44 Figura 2 - Questão 2 - Se entro seguidamente na Internet, quantas horas por dia passo na rede? Fonte: Da autora

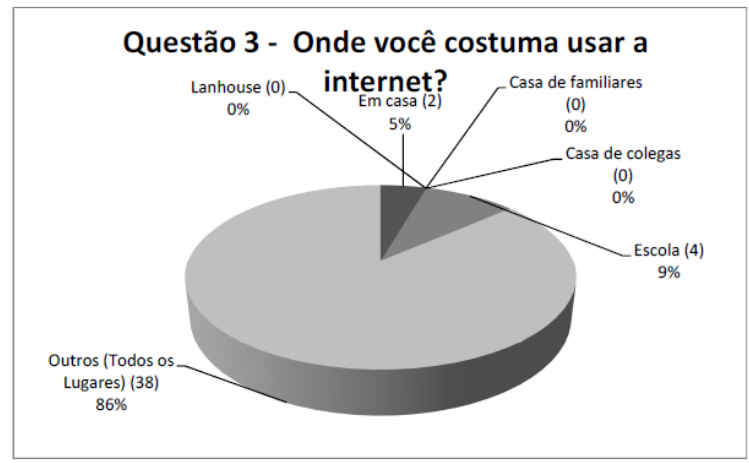

Figura 3 - Questão 3: Onde você costuma usar a internet?

Total respondentes: 44 Fonte: Da autora

Os números encontrados são muito superiores aos informados pela Pesquisa de Consumo de Mídia (Brasil, 2015) que menciona que, para pessoas 
entre 16 e 25 anos, a média de horas semanais na Internet seria de aproximadamente 6 horas, sendo este o grupo que mais passa tempo na Internet, segundo esta pesquisa. A partir dos dados levantados, pode-se pensar que o jovem deste grupo para além de vivenciar o mundo físico, também tem a necessidade de coexistir no mundo virtual com suas potencialidades e questões éticas que se impõe neste contexto. Os dados coletados apontam ainda que o uso da Internet é sobretudo voltado ao uso de redes sociais (38\%), entretenimento (32\%) e jogos (23\%). Usos recreativos neste público que contrabalançam com, por exemplo, "pesquisa", alternativa escolhida por somente $7 \%$ dos respondentes.

Os achados da pesquisa apontam que, embora a maioria do grupo pesquisado não foi vítima de cyberbullying, um número relevante de alunos/as (42\%, 19 respondentes) relatam terem sido vítimas ao menos uma vez, isso nos leva a refletir o quão importante é dialogar sobre este tema na escola e junto à comunidade.

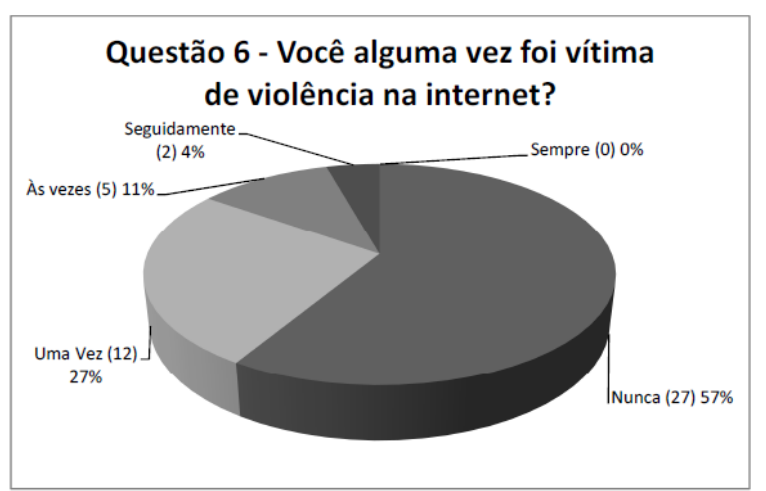

Total respondentes: 44

Figura 4- Questão 6: Você alguma vez foi vítima de violência na internet?

Fonte: Da autora

A partir dessas respostas, buscamos detalhar em outra questão as motivações do cyberbullying. Estabelecemos categorias prévias e colocamos o item "outros", para o caso de outras possibilidades não aventadas pelas alternativas anteriores

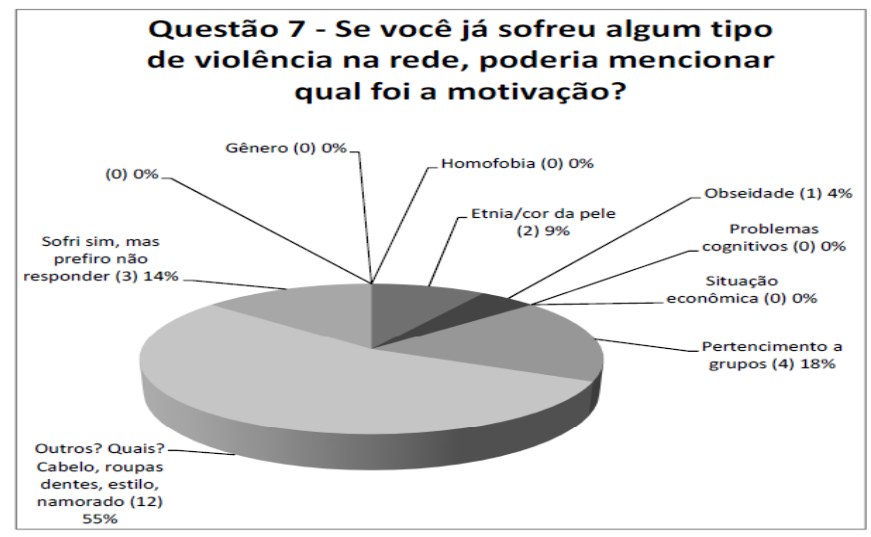

Total de respondentes: 22

Figura 5 - Questão 7 - Se você já sofreu algum tipo de violência na rede, poderia mencionar qual foi a motivação?

Fonte: Da autora

A questão 7 trouxe questões para problematizações importantes para a pesquisa: 
(1) o número de pessoas que comentam os motivos do cyberbullying (22 pessoas) é superior às que mencionaram terem sido vítimas de violência na Internet (19 respondentes). Essa incongruência pode apontar certa incompreensão, por parte dos respondentes, ou por problema na formulação da questão ou da delimitação entre o que seria bullying e o que não seria no momento da coleta de dados;

(2) 3 respondentes (14\%) disseram que sim, sofreram violência, mas que preferiam não comentar. Tal fato permite pensar em como a discussão dessas questões toca profundamente a subjetividade, a ponto de não querer comentar a situação sequer a um instrumento de pesquisa anônimo. Cabe pensar, ante esses apontamentos, entre outros, dois fatores que complexificam a discussão do cyberbullying no contexto estudado - (A) a vergonha de se considerarem vítimas de agressão e; (B) a possibilidade de não considerarem a agressão sofrida como cyberbullying, em função talvez, da banalização do abuso e da violência nas relações sociais;

(3) por outro lado a ocorrência de casos violência na Internet envolvendo questões raciais e de diversidade de gênero, que os registros da Orientação Educacional apontam existirem nas turmas, não se consubstanciaram no instrumento, pois o grupo respondente não apontou questões étnicas ou de homofobia como sendo motivação para o cyberbullying. Novamente, a questão da vergonha de se colocar como vítima de agressão pode estar atuando neste tópico, podendo estas respostas, inclusive, estarem acolhidas na alternativa "Sofri, sim, mas não quero comentar". Pensando que, dos 44 respondentes, somente 22 afirmam terem sofrido cyberbullyingao menos uma vez. Quanto aos 22 que não se manifestaram: ou realmente não foram vítimas de violência; ou não se consideraram vítima; ou ainda, apesar de terem sofrido violência, tiveram vergonha de se colocar neste local. Os dados coletados não trazem dados conclusivos sobre este aspecto

(4) chama atenção é a resposta "Outros" da questão 7. Ela foi a que teve o maior número de respostas. Houve apenas 22 (vinte dois) alunos respondentes, mas destes 12 (doze) alunos (as) sofreram algum tipo de agressão na rede estimulada por outros motivos que não os que foram questionados previamente tendo como respostas: cabelo, roupas, dentes, estilo e namorados.

Essa disparidade entre as categorias pressupostas no questionário como motivação e os motivos mencionadas pelos respondentes na categoria "Outros" podem ser indícios de que são necessários mais estudos sobre as dinâmicas da juventude na contemporaneidade, talvez de caráter mais etnográfico sobre a comunidade estudada, tais como os realizados por Dayrell (2007) e retomados por Arroyo (2007), em escolas públicas de Minas Gerais, que auxiliem no mapeamento do perfil e das demandas e das linguagens que estão sendo construídas nesta fase da vida.

Em função dos achados relatados, conectados aos apontamentos derivados dos registros da Orientação Educacional, apontam que o instrumento de coleta de dados empregado, embora traga elementos importantes para balizar algumas dinâmicas do cyberbullying no grupo estudado, precisa ser articulado a outros registros, de caráter mais qualitativo. Este conjunto inicial de dados apontam para a necessidade de compreensão dessas dinâmicas, e indicadores para futuros estudos, de como a questão do cyberbbulying se coloca em relação aos fluxos sociais mais amplos, sobretudo os referentes às culturas 
juvenis e de como todo esse conjunto complexo de fatores podem ser abordados a partir de uma perspectiva da cultura da e para a paz.

\section{CONSIDERAÇÕES FINAS}

Os dados apresentados apontam para uma apreciação inicial que um conjunto diminuto de questionamento sobre a vida on-line dos estudantes participantes do grupo respondente. O conjunto de dados apontam para a complexidade do problema e a necessidade de articulação entre aspectos quanti e qualitativos, desenvolvidos no trabalho monográfico ao qual este estudo se origina e que será desenvolvida em outro escrito. Os dados apontam para uma intensa conectividade do público respondente, maior do que a média nacional (BRASIL, 2015), e que ela se dá, sobretudo, através da telefonia móvel. Esses aspectos mereceriam ser apreciados pela instituição escolar, ainda mais que 0 uso dos celulares são atualmente proibidos na rede estadual de ensino (ASSEMBLEIA LEGISLATIVA DO RIO GRANDE DO SUL, 2008). Porém, essa perspectiva meramente proibitiva, ante os dados apresentados de alta conectividade dos estudantes neste estudo, necessita ser repensada. Trabalhos com mídias na educação que se valham da telefonia móvel para fomentar seus usos pedagógicos, cuja responsabilidade última é da instituição escolar. Somente com outras formas de se pensar metodologicamente os usos das tecnologias na Educação, dentre elas a telefonia móvel de forma que se potencializem outras referências de utilização que não somente os "usos recreativos", onde o letramento digital informal, circundante à escola, está operando.

Quanto à questão do cyberbullying, os dados apontam para a gravidade e a complexidade da questão e suas abordagens na escola, no contexto de uma cultura de paz. Os dados apontam que somente um instrumento como questionários individuais trazem elementos importantes, mas que somente ganham potência compreensiva frente ao cotejo com outros registros, como os registros da Orientação Escolar. Outras formas de coleta de dados, mais qualitativos, delimitados na monografia, não foram aqui apresentados, em função do espaço.

Os dados até o momento apresentado apontam para a maior necessidade de articulação entre métodos quantitativos e qualitativos de investigação deste tema. Indicam a necessidade de compreensão do fenômeno cyberbullying no entorno a dinâmicas mais amplas das culturas juvenis, conforme aponta Dayrell (2007) na medida em que as formação de mediação das relações interpessoais via Internet, sobretudo com o uso das redes sociais, podem estar provocando modulações nas já diversas formas de ser jovem. Os resultados sugerem também a elaboração de outras abordagens sobre o tema, a promover o protagonismo juvenil, valorizando os jovens como sujeitos sociais produtores de cultura, visões de mundo sobre as coisas, inclusive sobre o cyberbullying, desconstruindo uma visão audultocêntrica sobre o tema. Futuros escritos irão perscrutar essas possibilidades.

\section{REFERÊNCIAS}

ARROYO, Miguel G. Imagens quebradas: trajetórias e tempos de alunos e mestres. Ed. Vozes: Petrópolis. 2007. 
ASSEMBLEIA LEGISLATIVA DO ESTADO DO RIO GRANDE DO SUL. LEI № 12.884, DE 03 DE JANEIRO DE 2008. Dispõe sobre a utilização de aparelhos de telefonia celular nos estabelecimentos de ensino do Estado do Rio Grande do Sul. Documento disponível em:

http://www.al.rs.gov.br/filerepository/repLegis/arquivos/12.884.pdf. Acesso em 27 out. 2015.

BEUST, Luís Henrique. O valor dos valores na educação. In: Revista Diálogo, Ano X, n. 37, p. 14-18, fev. 2005.

A galáxia da internet. Rio de Janeiro: Zahar, 2003.

BRASIL. Presidência da República. Pesquisa Brasileira de Mídia 2015. Hábitos de consumo de mídia pela população brasileira. Brasília: Secretaria de Comunicação da Presidência. Documento disponível em: http://www.secom.gov.br/atuacao/pesquisa/lista-de-pesquisas-quantitativas-equalitativas-de-contratos-atuais/pesquisa-brasileira-de-midia-pbm-2015.pdf Acesso em 10 set.2015.

DAYRELL, J. T. A escola "faz" as juventudes? Reflexões em torno da socialização juvenil. Educ. Soc., Campinas, vol. 28, n. 100 - Especial, p. 1105 -1128 , out. 2007.

FANTE, Cleodelice Aparecida Zonato. Fenômeno bullying: como prevenir a violência nas escolas e educar para paz. 2. ed. Campinas, São Paulo: Veros, 2005.

FANTE, Cleodelice Aparecida; PEDRA, José Augusto. Bullying escolar: perguntas \& respostas. Porto Alegre: Artmed, 2008.

GUIMARÃES, Marcelo Rezende. Educação para a paz: sentidos e dilemas. Caxias do Sul: EDUCS, 2006.

GRINSPUN, Mirian P. S. Z. Educação Tecnológica. In

Educação Tecnológica: desafios e perspectivas. 2. ed. São Paulo: Cortez, 1999.

(Org.). Supervisão e orientação educacional: perspectivas de integração na escola. São Paulo: Cortez, 2003.

LÉVY, P. Cibercultura. 2. ed. São Paulo: Editora 34, 2001.

. A inteligência coletiva: por uma antropologia do ciberespaço. 4. ed.

São Paulo: Loyola, 2003.

MALDONADO, Maria Tereza. Bullying e ciberbullying: o que fazemos com o que fazem conosco? São Paulo: Moderna, 2011. Disponível em:

<http://www2.fcsh.unl.pt/eukidsonline/docs/LivroActas.pdf>. Acesso em: 06 mar. 2015.

MARTINS, P. O., TRINDADE, Z. A. O Ter e o Ser: representações sociais da adolescência entre adolescentes de inserção urbana e rural. Psicologia: Reflexão \& Crítica, v. 16, n. 3, p. 555-568, 2003.

MATOS, A., Pessoa, T., Amado, J. \& Jäger, T. (2009) "Cyberbullying: o desenvolvimento de um manual para formadores". Livro de actas Conferência Nacional 3 de Julho de 2009. Disponível em: http://ticeduca.ie.ul.pt/atas/pdf/324.pdf. Acesso em: 15 abril. 2015.

MINAYO, Maria Cecilia de Souza; Suely Ferreira Deslandes; Otavio Cruz Neto, Romeu Gomes; (Orgs.) Pesquisa social: teoria, método e criatividade. Petrópolis, RJ: Vozes, 2002. $21^{\text {a }}$ ed.

OLWEUS, Dan. Bullying at school: what we know and what we can do. Malden:

Blackwell, 2006.

ONU. Declaração e Programa de Ação sobre uma Cultura de Paz. Disponível 
em:.www.comitepaz.org.br/dec_prog_1.htm. Genebra: 1999 Acesso em: 01/05/2015.

RECUERO, Raquel da Cunha. Redes Sociais na Internet. Sulina, 2009. 